\title{
COMPREENSIBILIDADE DE LEITURA DOS ESTUDANTES DE CIÊNCIAS CONTÁBEIS POR MEIO DA TÉCNICA CLOZE
}

\author{
Daniela Aparecida Vuolol \\ Lara Fabiana Dallabona2 \\ Caroline Sulzbach Pletsch3
}

- Artigo recebido em: 20/08/2016 -- Artigo aceito em: 16/04/2018 -- Segunda versão aceita em: 18/04/2018

\section{RESUMO}

O estudo objetiva analisar a compreensibilidade de leitura dos estudantes de ciências contábeis em relação a assuntos envolvendo o profissional contábil, por meio da técnica cloze. Para tanto, desenvolveu-se pesquisa descritiva, de levantamento e quantitativa, com utilização da estatística descritiva. A amostra compreendeu 145 estudantes matriculados no curso de ciências contábeis de uma universidade do Sul do Brasil, no primeiro semestre de 2015, que responderam ao instrumento de pesquisa entre os dias 11 a 20 de maio de 2015. Quanto à compreensibilidade de leitura, o estudo utilizou seis textos de temas relacionados à profissão contábil, baseados em referências extraídas dos planos de ensino da universidade, sendo: ética profissional, contabilidade l, contabilidade de custos, contabilidade tributária, auditoria, legislação trabalhista e previdenciária. Os resultados demonstram que os temas mais específicos da área contábil, tais como, contabilidade de custos, contabilidade tributária e auditoria, são assuntos de menor compreensibilidade na leitura. A ética profissional que é um tema habitual para todas as profissões e a contabilidade I que envolve conhecimentos básicos sobre a contabilidade, foram os temas que obtiveram os maiores percentuais de compreensibilidade de leitura, $40 \%$ e $32 \%$ respectivamente. De modo geral, a maioria dos estudantes não possuem habilidade de leitura suficiente, dificultando a compreensão do texto de cada tema, e assim não respondendo completamente os questionários com a aplicação da técnica Cloze.

Palavras-chave: Compreensibilidade de Leitura. Estudantes. Ciências Contábeis. Técnica Cloze.

1 Graduada em Ciências Contábeis. Universidade do Estado de Santa Catarina (UDESC). Endereço: Rua Dr. Getulio Vargas, 2822, Bela Vista, Ibirama, 89.140-000. E-mail: danielavuolo@hotmail.com. Telefone: (47) 9617 - 2313.

2 Doutora em Ciências Contábeis e Administração. Universidade do Estado de Santa Catarina (UDESC). Departamento de Ciências Contábeis. Endereço: Rua Dr. Getulio Vargas, 2822, Bela Vista, Ibirama, 89.140-000. E-mail: lara.dallabona@udesc.br. Telefone: (47) 3357 - 8444.

3 Mestre em Ciências Contábeis. Universidade do Estado de Santa Catarina (UDESC). Departamento de Ciências Contábeis. Endereço: Rua Dr. Getulio Vargas, 2822, Bela Vista, Ibirama, 89.140-000. E-mail: caroline.pletsch@udesc.br. Telefone: (47) 3357 - 8444. 


\title{
READING UNDERSTANDING OF SCIENCES STUDENTS BY TECHNICAL CLOZE
}

\begin{abstract}
The study aims to analyze the comprehensibility reading of students accounting sciences in relation to matters involving the accounting professional, through cloze technique. Therefore, we developed descriptive research, survey and quantitative, using descriptive statistics. The sample included 145 students enrolled in the accountancy course at a university in southern Brazil, in the first half of 2015, responded to the instrument from 11 to 20 May 2015. As for the comprehensibility of reading, study used six texts of issues related to the accounting profession based on references obtained from the university teaching plans, as follows: professional ethics; Accounting l; cost accounting; tax accounting; audit and labor and social security legislation. The results show that the more specific issues of accounting, such as cost accounting, tax accounting and auditing are matters less comprehensibility in reading. Professional ethics is a common theme for all professions and accounting I that involves basic accounting, were the themes that had the highest percentage of comprehensibility in reading, $40 \%$ and $32 \%$ respectively. Generally speaking, most scholars do not have sufficient reading skills, making it difficult to understand the text of each subject, and so not quite answering the questionnaires in the application of Cloze technique.
\end{abstract}

Keywords: Read Comprehensibility. Students. Accounting. Cloze technique.

\section{INTRODUÇÃO}

Para que qualquer organização seja bem estruturada e fácil de ser controlada é preciso o uso da contabilidade, que é a ciência que criou uma metodologia própria a fim de controlar o patrimônio das entidades, assim como apurar o resultado das atividades e prestar informações por meio de relatórios aos interessados em avaliar a situação patrimonial e desempenhos destas entidades (NEVES; VICECONTI, 2006).

Nasi (1994) relata que a função do contador em uma organização é a de um analista competente, que interpreta, dirige e dá apoio ao processo de tomada de decisões. Para cumprir sua função, uma das características importantes do profissional da contabilidade é a necessidade de compreensão, - contador precisa compreender ações, analisar minuciosamente as organizações, para antecipar e promover suas transformações.

A leitura e compreensão são ferramentas de fundamental importância para a inserção de um profissional na sociedade, ainda mais este sendo profissional de contabilidade. A habilidade de compreensão da leitura se torna significativa e indispensável durante o processo de formação acadêmica, que tem como um dos objetivos ensinar os conceitos por meio de práticas que exigem esse tipo de habilidade (SANTOS et al., 2002). 
Buscando um diferencial competitivo, segundo Amaral (2012), é constantemente crescente o número de empresas que vêm investindo em meios que apresentem informações estratégicas a fim de permitir aos gestores tomadas de decisões mais seguras e de forma proativa. Neste sentido Horngren (1986) menciona que além do dever de cumprir com as exigências estabelecidas pela Legislação, uma das principais tarefas do contador é facilitar a compreensão das informações contábeis aos administradores, comprovando a importância da contabilidade no processo decisório.

Conforme Lang e Zanchett (2007), o diferencial de um profissional de sucesso pode estar relacionado com a sua habilidade de compreensão de leitura. Possivelmente, este atributo bem desenvolvido, permitirá que o contador entenda as informações de sua atuação, proporcione o conhecimento necessário para tomada de decisões e, por meio deste procedimento de aprendizagem, constitua de forma atualizada o perfil de um bom profissional. Deste modo em 1953, Taylor com o objetivo de mensurar a compreensibilidades de leitura das pessoas, introduziu uma nova técnica denominada Cloze. Para a aplicação da técnica é selecionado um trecho de um texto com aproximadamente 200 vocabulários, do qual, omite-se do trecho original alguma palavra em que os examinados devem preencher, essas palavras são analisadas em relação as corretas (SANTOS et al., 2002).

Costa (2006) menciona que a técnica Cloze tem sido utilizada na área contábil para avaliação da compreensibilidade, tanto de livros textos (ADELBERG; RAZEK, 1984; STEVENS, Kathleen; STEVENS, Kevin; STEVENS, William, 1993; ANDRADE; MARTINS, 2003), quanto de relatórios contábeis e financeiros. Utilizando-se esta técnica, foram identificadas divergências quanto à compreensibilidade entre os usuários e os preparadores de relatórios financeiros (ADELBERG, 1979; SMITH; TAFFLER, 1992).

Monello (2015), membro do CRC/SP, explica que o profissional da contabilidade no dia a dia das organizações é de extrema importância, pois a transparência das organizações é cada vez mais exigida na prestação de contas, tanto para aumentar sua confiabilidade na sociedade quanto para uma gestão eficaz em suas idealizações.

Diante da contextualização a pergunta que norteia o estudo é: Qual a compreensibilidade de leitura dos estudantes de ciências contábeis de uma universidade do Sul do Brasil em relação a assuntos envolvendo o profissional contábil? O objetivo do estudo visa analisar a compreensibilidade de leitura dos estudantes de ciências contábeis de uma universidade do Sul do Brasil em relação a assuntos envolvendo o profissional contábil, por meio da técnica Cloze.

Estudos já desenvolvidos sobre o tema verificaram se os livros de contabilidade utilizados nos cursos introdutórios são de fato compreensíveis (ANDRADE, 2004), aplicaram a técnica Cloze para avaliar a compreensão dos universitários em relação a leitura (SANTOS et al., 2006), desenvolveram uma pesquisa para identificar, por meio da aplicação da técnica Cloze, se os alunos concluintes do curso de Administração apresentam um nível de leitura mais elevado do que os ingressantes (LANG; ZANCHETT, 2007), desenvolveram um estudo apresentando a importância da leitura que viabiliza às informações para 
a boa atuação do profissional contábil e para os estudantes da área (BOFF et al., 2008).

Pesquisas com enfoque para estudantes de todas as fases de um curso de ciências contábeis são incipientes, o que possibilita o desenvolvimento de pesquisas para identificar o entendimento dos estudantes sobre assuntos técnicos na área. Desta forma, do ponto de vista social, o estudo se justifica, pois, uma das maiores dificuldades educacionais que a população brasileira enfrenta, de acordo com algumas pesquisas analisadas, é a falta de compreensão leitora e o analfabetismo funcional e técnico. Na perspectiva prática, o estudo proporcionará aos docentes, discentes e pesquisadores em geral, aperfeiçoamento do conhecimento quanto à compreensibilidade de leitura dos assuntos envolvendo a área contábil.

Outra contribuição decorre do desenvolvimento de um estudo que aprofundará os conhecimentos teóricos em relação à compreensibilidade da leitura na formação do profissional contábil, pois um dos diferenciais dos profissionais de sucesso é a habilidade de compreensão dos dados para gerar informações que auxiliarão seus respectivos usuários na tomada de decisões.

\section{REFERENCIAL TEÓRICO}

Para fundamentar o estudo, é abordado no referencial teórico aspectos relacionados a compreensão e comunicação na leitura, técnica Cloze e estudos anteriores.

\subsection{Compreensão e Comunicação na Leitura}

Ler é uma habilidade que faz parte do dia a dia, entretanto, segundo Vicentelli (1999), a realização da leitura não é tão simples como pode ser julgada. Em uma visão mais ampla, ler significa compreender o que foi lido. É preciso que o leitor atribua significado à sua leitura.

O objetivo da leitura, de acordo com Silva e Gabriel (2005), é a compreensão do que outras pessoas pensam. Portanto, essa tarefa exige uma visão crítica dos assuntos lidos, desenvolvendo as tarefas de examinar, identificar, comparar, localizar, avaliar, selecionar e priorizar informações.

Ao tratar de compreensão de leitura, Silva (2005) relata que a leitura e compreensão do texto dependem exclusivamente de quem o lê. É importante que se tenha uma relação dinâmica entre o texto e o leitor, a partir dessa interação se forma um terceiro elemento, que é a compreensão. Neste mesmo sentido, Costa (2006) afirma que o leitor relaciona a nova informação com a representação já existente em memória, e produz a compreensão.

Para realizar a leitura e compreensão, é indispensável a existência de um prévio conhecimento sobre o assunto do qual se lê, favorecendo a correlação dos dados e informações para desenvolver um novo entendimento. O leitor tem a responsabilidade de interação entre seus conhecimentos de mundo e com as informações do texto para atingir a compreensão (SILVA, 2005).

Diante de um mesmo texto, é possivel a interpretação diferenciada dos leitores, o que pode ser extremamente complexo para um, poderá ser obvio para

4 Revista Contabilidade Vista \& Revista, ISSN 0103-734X, Universidade Federal de Minas Gerais, Belo Horizonte, v. 29, n. 1, p.01-27, jan./abr. 2018 
outro (ANDRADE, 2004). Ao fazer uma relação entre previsibilidade e compreensão, Andrade (2004) relata que quanto maior a previsibilidade, menor a incerteza, aumentando a perspectiva de maior facilidade de compreender a mensagem.

Devido aos fatores diversos envolvendo os aspectos quanto aos leitores que processam a leitura referente ao texto, torna-se viável a realização de avaliação da compreensão de leitura. Como o estudo está voltado para a avaliação da compreensão dos alunos, buscou-se uma técnica conveniente para tal situação, denominada técnica Cloze. Boff et al. (2008) destacam que a prática da leitura precisa fazer parte do dia a dia dos estudantes, entretanto, na graduação, são exigidos níveis mais avançados de compreensão.

Witter (1999) menciona que, na universidade, a habilidade em leitura é essencial para o processo de ensino e aprendizagem, podendo ser a última oportunidade formal para que o cidadão se torne um leitor com capacidade de compreender e utilizar as informações dos textos de forma crítica e adequada.

Silva (2003, p. 18) destaca que "Ao deparar com a necessidade de leitura de textos filosóficos e técnicos, na área contábil, o estudante sente certa dificuldade de compreensão. Acredita-se que, por falta de leitura, essas dificuldades agravam-se". A capacidade de expressão e argumentação são características básicas em qualquer profissional. Portanto para o profissional contábil este atributo não é diferente, o contador precisa ter a capacidade de captar as informações da melhor maneira, repassar estas informações a seus usuários de forma fidedigna (MACHADO, 2002).

\subsection{Técnica Cloze}

No campo educativo, em 1953, partindo do princípio de fechamento "closure" da psicologia de Gestalt, Wilson L. Taylor introduziu o Cloze. O teste consiste na organização de um texto de aproximadamente 250 palavras, do qual se omite vocábulos e se solicita ao leitor que substitua por palavras que melhor façam sentido ao texto (CUNHA, 2009).

Sua aplicação, conforme Andrade (2004) se dá retirando palavras de um determinado texto, e substituindo por espaços em branco de igual tamanho, independentemente do tamanho da palavra retirada. Quando o respondente completar os espaços em branco com a palavra igual à que foi retirada, ou alternativamente, palavra sinônima, é considerada um acerto. Porém caso seja preenchida com palavra diferente ou simplesmente não responder, será considerado um erro. Taylor (1953) explica que o resultado do teste é representado pelo número de palavras que o respondente acerta.

Segundo Molina (1979), Taylor apresentou a técnica denominada de "Cloze" como uma nova medida de inteligibilidade, livre de muitas desvantagens dos métodos tradicionais, visto por ele. Nesta técnica são retiradas palavras dos textos, substituindo por espaços vazios que o respondente deve preencher com uma palavra tentando adivinhar a correta.

De acordo com Bormuth (1968), na formula original do teste, pode ser feito - lacunamento rígido, em que se apaga rigorosamente após a primeira frase, cada quinta, sétima, ou décima palavra do texto, ou de forma racional, em que 
as palavras a serem omitidas são escolhidas de acordo com os objetivos do avaliador.

Taylor (1953) chama a atenção para a técnica, por ser muito mais simples de ser elaborada, diferente dos testes de compreensão tradicionais. Têm sido aplicados a diversas finalidades como: medição da inteligibilidade de textos, construção de exercícios para treino em remediação de leitura, medida de compreensão de leitura, ganho de informação como função da leitura, e por muitas vezes como instrumento para diagnóstico clínico.

A compreensão em leitura requerida pela técnica Cloze envolve, entre outras variáveis, a habilidade do leitor em estabelecer relações entre os elementos do texto e a sua capacidade de desenvolver associações apropriadas entre o conhecimento prévio e a informação (DIAS; SILVEIRA, 2014).

Carrel e Carson (1993) evidenciam que a técnica Cloze força o leitor a utilizar o contexto para prever o significado $e$, assim, refletir e mensurar a compreensão em leitura. Leffa (1996, p. 70) destaca que "como instrumento de ensino de leitura, a técnica Cloze é capaz de desenvolver no leitor a percepção de aspectos importantes do texto".

Oliveira et al. (2009) apresentam 10 tipos diferentes do teste, a escolha do método de organizar o teste vai depender do objetivo que se pretende atingir. Os diferentes tipos de teste mensuram diferentes habilidades, que na maioria das vezes, apresentam diagnósticos uteis (ALDERSON, 1996). Independente da escolha do tipo do teste a ser utilizado, dentre as vantagens incluem o seu fácil preparo e aplicação (KLEIMAN, 1983).

Vários estudos já foram desenvolvidos utilizando a técnica Cloze, como por exemplo: o estudo de Santos et al. (2006), apontando que a técnica Cloze é adequado para a identificação da compreensão em leitura de universitários. 0 estudo destacou a baixa compreensão dos universitários iniciantes, comparado com o nível de compreensão dos universitários concluintes. Santos et al. (2006) mencionam outros estudos, como os de Alvarez (1990) e Pellegrini (1996). Na sequência, demonstram-se estudos relevantes identificados na literatura envolvendo a temática da pesquisa.

\subsection{Estudos Anteriores}

O desenvolvimento do estudo decorre da leitura de alguns trabalhos publicados em anais de congressos, dissertações, livros e periódicos nacionais dos quais abordaram a técnica Cloze, contribuindo desta forma, para consecução deste estudo. As pesquisas localizadas são descritas neste estudo de forma breve.

Andrade (2004) utilizou a técnica Cloze em uma pesquisa desenvolvida e aplicada no curso de Ciências Contábeis do Departamento de Contabilidade e Atuária da Faculdade de Economia, Administração e Contabilidade da Universidade de São Paulo, tendo como questão de pesquisa: Os livros de contabilidade utilizados nos cursos introdutórios são de fato compreensíveis? As palavras analisadas dos textos foram retiradas de dois livros de contabilidade introdutória mais adotadas pelas universidades públicas brasileiras. Ao contrário dos estudos anteriores, pelo conhecimento do autor, no resultado houve a falta de relação entre o desempenho na técnica Cloze e o nível de formação do 
estudante, bem como desempenho na disciplina. O estudo concluiu ainda que os livros são adequados aos períodos considerados.

Costa et al. (2005) desenvolveram um estudo com o objetivo de verificar a existência da relação entre o desempenho obtido pelos alunos na disciplina de Contabilidade de Custos I e os resultados da técnica Cloze. Os participantes foram os 31 alunos da disciplina de Contabilidade de Custos I do curso de graduação de Ciências Contábeis da Universidade Federal do Rio Grande do Norte (UFRN). Selecionaram um trecho do livro de Contabilidade de Custos adotado na disciplina para aplicação da técnica Cloze. Concluíram que a obtenção de maior número de acertos no teste não indica que o aluno irá obter um bom desempenho na disciplina em análise. Porém, ressaltaram que os alunos que não conseguem obter um nível compreensível na leitura do texto, podem ter desempenho ruim no decorrer da disciplina.

Santos et al. (2006) evidenciaram que a aplicação da técnica Cloze é adequada para avaliar a compreensão dos universitários, referente a leitura. Com o estudo obtiveram resultados de baixo nível de compreensão dos universitários iniciantes, comparado com os resultados obtidos dos universitários concluintes.

Lang e Zanchet† (2007) realizaram uma pesquisa visando identificar o grau de compreensão dos acadêmicos de fases iniciantes comparada com os que cursam fases finais. Foi aplicado a técnica Cloze com 138 alunos do curso de Administração. Como resultado, os alunos iniciantes obtiveram $41,75 \%$ de acertos contra $39,85 \%$ de acertos dos alunos concluintes. $O$ artigo sugere novas pesquisas para melhorar a compreensão da leitura dos acadêmicos, já que o resultado apresentado não se confirmou com o pressuposto inicial.

Sélis (2008) objetivou em sua pesquisa identificar a compreensão e estratégia de aprendizagem em universitários do curso de Letras de uma IES do interior de Tocantins. $O$ instrumento de pesquisa foi realizado por meio da técnica Cloze e escala de avaliação de estratégia. Os respondentes foram acadêmicos da primeira fase comparando com os da oitava fase. Os resultados obtidos provaram que há serias dificuldades na compreensão de leituras e não apresentou diferenças significativas entre os que cursam as fases iniciais e os de fases finais.

Cunha (2009) com o intuito de analisar o nível de compreensão de leitura e produção de texto, realizou uma aplicação da técnica Cloze para 202 alunos de vários cursos de graduação de uma universidade particular do interior de São Paulo. Os resultados encontrados se confirmaram com os estudos anteriores de conhecimento do autor, em que permitiram encontrar relações significativas entre as medias obtidas na técnica Cloze e na avaliação de interpretação de texto.

Dallabona, Beuren e Rodrigues (2012) realizaram um estudo com o objetivo de investigar a compreensibilidade de livros de Sistemas de Informações por meio da aplicação da técnica Cloze em 136 alunos de mestrado e doutorado em Ciências Contábeis. Os resultados obtidos não condizem com o resultado esperado, já que o estudo foi motivado pela expectativa dos livros de sistemas de informações traduzidos do inglês para o português apresentassem maior 
dificuldade de compreensão, por se tratar de uma obra produzida em uma diferente cultura, tecnologia e idioma. O que se verificou com o estudo é que esses fatores não interferiram no resultado e que diversos respondentes tiveram maior dificuldade de compreensão da obra produzida no Brasil.

Bortolanza (2012) desenvolveu um estudo com o objetivo de mostrar que a técnica Cloze pode ser um instrumento válido para melhoria do desenvolvimento em leituras de alunos do ensino fundamental. Aplicou 3 testes semanais durante um mês em 12 alunos, e no final aplicou um teste para outros 12 alunos que não haviam participado antes. Os resultados se confirmaram com o objetivo da pesquisa, mostraram que a técnica cloze pode ser eficiente para a melhoria do desempenho em leitura, possibilitando aos alunos superarem dificuldade de leitura, ou desenvolverem estratégias de compreensão.

Esta pesquisa se difere dos estudos apresentados, haja vista, que busca verificar a compreensão dos estudantes de ciências contábeis de uma instituição de ensino superior pública sobre assuntos que envolvem o profissional contábil, fazendo uso da técnica Cloze.

\section{PROCEDIMENTOS METODOLÓGICOS}

A pesquisa caracteriza-se como descritiva, de levantamento e quantitativa. Conforme dados repassados pela secretaria acadêmica da universidade, no primeiro semestre de 2015, a população envolve 294 estudantes vinculados ao curso de graduação em Ciências Contábeis. A escolha por aplicar a pesquisa nesta universidade se deve a viabilidade de poder aplicar pessoalmente os questionários, podendo esclarecer as possíveis dúvidas da pesquisa, e chegar o mais próximo possível da amostra desejada. Também por questão de ser uma universidade pública, sugerindo estudos futuros aplicados em universidades particulares, para comparações.

A amostra de pesquisa é não probabilística e intencional, compreendendo 145 estudantes que responderam ao instrumento de pesquisa, envolvendo acadêmicos de todas as fases do curso. Amostragem não probabilística compreende aquela em que a seleção dos elementos da população para a composição da amostra depende do julgamento do pesquisador (MATTAR, 1996). A amostra intencional, segundo Costa Neto (1977), consiste em selecionar, com base nas informações disponíveis, um subgrupo da população que possa representar toda a população.

Para a coleta de dados, a partir das ementas foram escolhidas intencionalmente as disciplinas e temas do eixo profissionalizante do curso. Em seguida, por meio do site da instituição, foram extraídas dos planos de ensino de cada disciplina as bibliografias bases utilizadas pelos professores, conforme Tabela 1. 
Tabela 1 - Referências utilizadas para elaboração do questionário

\begin{tabular}{c|l|l}
\hline Fases & \multicolumn{1}{|c}{ Disciplinas } & \multicolumn{1}{c}{ Referências } \\
\hline $1^{a}$ & Contabilidade I & $\begin{array}{l}\text { Iudícibus, S. Contabilidade introdutória. 11.ed. São } \\
\text { Paulo: Atlas, 2010. }\end{array}$ \\
\hline $3^{a}$ & Contabilidade de Custos & $\begin{array}{l}\text { Martins, E. Contabilidade de custos. 9a ed. São } \\
\text { Paulo: Altas, 2003. }\end{array}$ \\
\hline $3^{a}$ & Contabilidade Tributária & $\begin{array}{l}\text { Fabretti, L. C. Contabilidade Tributária. 1 1 } 1^{a} \text { Ed. São } \\
\text { Paulo. Atlas, 2007. }\end{array}$ \\
\hline $4^{a}$ & $\begin{array}{l}\text { Legislação Trabalhista e e } \\
\text { Previdenciária }\end{array}$ & $\begin{array}{l}\text { Nascimento, A. M. Iniciação ao Direito do } \\
\text { Trabalho. 2a ed., São Paulo: LTR, 2009. }\end{array}$ \\
\hline $6^{a}$ & Ética Profissional & $\begin{array}{l}\text { Lisboa, L. P. Ética geral e profissional em } \\
\text { contabilidade. Atlas, São Paulo, 1997. }\end{array}$ \\
\hline $7^{a}$ & Auditoria & $\begin{array}{l}\text { Attie, W. Auditoria: conceitos e aplicações. 6. ed. } \\
\text { Altas: São Paulo, 2011. }\end{array}$ \\
\hline
\end{tabular}

Fonte: Dados da pesquisa.

A disciplina de contabilidade I tem como um dos objetivos proporcionar aos estudantes noções preliminares de contabilidade. A Contabilidade de acordo com Ribeiro (1997), é uma ciência que por meio de suas técnicas, permite o controle do patrimônio das entidades.

Martins (2003) destaca que a contabilidade de custos tem como finalidade mensurar, registrar e relatar informações sobre o custo. É um ramo da contabilidade que proporciona aos usuários das informações auxiliarem no planejamento da empresa e os respectivos controles, assim como suporte para tomadas de decisões. Referente à disciplina de contabilidade tributária, Fabretti (2007) demonstra que esta área da contabilidade tem por objetivo aplicar na prática, de forma simultânea e apropriada, os conceitos, princípios e normas básicas da contabilidade e da legislação tributária. Devendo ainda, demonstrar de forma clara e precisa a situação patrimonial e o resultado do exercício.

A Legislação Previdenciária e Trabalhista refere-se a um conjunto de normas que regulam as condições do trabalho humano assalariado, bem como os direitos e os deveres de empregados e empregadores (SOIBELMAN, 1981). Neste sentido existe a Consolidação das Leis do Trabalho (CLT), que tem como principal objetivo a regulamentação das relações individuais e coletivas do trabalho, nela prevista.

Lisboa (1997) descreve que a Ética tem como finalidade investigar e explicar o comportamento das pessoas ao longo das várias fases da história. Para Vásquez (2002), a Ética parte do fato da essência da moral, ou seja, define como ponto inicial a diversidade de moral no tempo com seus respectivos valores, princípios e normas.

A auditoria é uma especialização da contabilidade direcionada a testar a eficiência e eficácia do controle patrimonial implantada com o objetivo de 
expressar uma opinião sobre determinado dado. De modo geral, a auditoria tem por base a análise conjunta de quatro elementos: critério, condição, causa e efeito (ATTIE, 2011).

Com base nas disciplinas e bibliografias apresentadas na Tabela 1, foram retirados dos livros alguns trechos, para realizar a técnica Cloze. Segundo Andrade e Martins (2003, p. 5), para elaborar a técnica "uma seção de um texto é selecionada, nela eliminamos sistematicamente as palavras e neste lugar colocamos um espaço em branco de igual tamanho para todas as palavras deletadas".

Da mesma forma Adelberg e Razek (1984), elencam alguns passos para a elaboração e avaliação da técnica Cloze. Primeiramente são escolhidos trechos do texto aleatoriamente, a partir da primeira frase, toda quinta palavra será retirada e substituída, neste caso por 10 espaços em branco.

O respondente pela primeira vez em contato com o trecho já com os espaços em branco, deverá preencher com a palavra que achar correta. A palavra completada para estar correta, deverá ser idêntica, ou alternativamente, palavra sinônima, retirada do texto. Para identificar os trechos que proporcionaram maior entendimento, basta somar os acertos.

Antes de aplicar o instrumento de pesquisa envolvendo os estudantes definidos na amostra, foi realizado um pré-teste com professores do Departamento de Ciências Contábeis da Universidade. O pré-teste foi enviado via e-mail para 9 (nove) professores, no decorrer do mês de maio/2015, dos quais 5 (cinco) responderam ao instrumento sugerindo alterações.

Inicialmente o questionário para o pré-teste continha textos de todas as fases, porém conforme sugestões referentes a extensão do questionário, foram eliminados alguns textos. As demais alterações sugeridas e consideradas válidas foram atendidas.

Para a aplicação da pesquisa envolvendo os estudantes do curso de Ciências Contábeis, primeiramente solicitou-se autorização ao coordenador do Curso de Ciências Contábeis da instituição de ensino envolvida, bem como aos professores lotados no departamento (efetivos e contratados) para aplicação da pesquisa e posteriormente, via e-mail, solicitou-se a disponibilidade do melhor dia e horário para aplicar os questionários de forma presencial.

Uma carta de apresentação demonstrando o objetivo do estudo, as possibilidades de desistência ou interrupção na participação, informações de que a desistência não causaria nenhum prejuízo à saúde e bem-estar físico, que os dados dos respondentes seriam mantidos em sigilo e que concordavam que os resultados fossem divulgados em publicações científicas foram apresentados aos participantes.

O questionário utilizado na respectiva pesquisa constituiu-se de perguntas abertas e fechadas para identificação dos respondentes, e posterior, aplica-se os textos sobre as disciplinas do curso, para identificar a compreensibilidade na leitura dos estudantes do curso. Para a tabulação da técnica Cloze, levou-se em consideração as palavras idênticas retiradas do texto, e as sinônimas, ou seja, aquelas que não fossem iguais ao texto, mas que mantinham o sentido da frase. 
Estas foram consideradas corretas para identificar a compreensibilidade de leitura dos estudantes em relação a cada texto. A tabulação dos dados foi realizada por meio de planilhas eletrônicas do Microsoft Excel, elaborando uma tabela para cada texto. A pontuação atribuída foi de 0 (zero) para as palavras incorretas, e 1 para palavras idênticas ou sinônimas.

Posterior utiliza-se estatística descritiva comparando os percentuais de respostas corretas, ao número de erros e lacunas em branco. Normalmente, a concepção dos escores da técnica Cloze é atribuída em três níveis de leitura, sendo que um percentual de até $44 \%$ de acertos indica que o leitor obteve poucas informações da leitura e, portanto, obteve pouco êxito na compreensão. Um percentual entre 44 a $57 \%$ de acerto mostra que a compreensão da leitura é suficiente, mas depende de auxilio adicional externo. E um nível de acertos acima de $57 \%$ equivale a um nível alto de compreensão do leitor (ADELBERG, 1979; SMITH; TAFFLER, 1992; SANTOS et al., 2002).

\section{DESCRIÇÃO E ANÁLISE DOS RESULTADOS}

Neste capítulo apresenta-se as características dos respondentes, a compreensibilidade da leitura dos estudantes envolvendo assuntos contábeis e análise comparativa da compreensibilidade de leitura.

\subsection{Características dos Respondentes}

Os estudantes, em sua totalidade, residem em 15 (quinze) cidades diferentes. Considerando toda a amostra da pesquisa, predominou a cidade da Instituição, com 64 estudantes.

Os dados demonstram que $66 \%$ do total dos respondentes são mulheres. Os estudantes que participaram da pesquisa possuem na sua maior proporção idade até 20 anos (63 estudantes) e em menor proporção idade acima de 30 anos (8 estudantes), deduzindo uma população de jovens, que provavelmente saíram do Ensino Médio e já iniciaram a graduação. Três estudantes da amostra não identificaram a idade.

A pretensão de educação continuada predominante encontrada foi para Pós-Graduação/Especialização (46\% dos estudantes), sendo importante destacar que esta pergunta da pesquisa permitia que o respondente escolhesse mais de uma alternativa.

Porém, de acordo com a pesquisa realizada para este estudo, 54\% dos respondentes não trabalha na área, ou seja, 78 estudantes atuam em outras áreas ou estão desempregados. Verificou-se que foram 20 áreas diferentes de atuação, se destacando o comércio, que emprega o maior percentual $(25 \%)$ destes estudantes. Tais resultados podem ser justificados, pois o comércio necessita indiretamente de funcionários com conhecimento na área contábil, o que desenvolve e engrandece o estabelecimento comercial e o profissional.

Observou-se que $31 \%$ dos envolvidos na pesquisa trabalham na área, e 15\% não, mas tem a pretensão de atuar na área contábil. Dos 20 estudantes que precisaram mudar de cidade, apenas 5 (cinco) trabalham na área e 4 
pretendem, os outros 11 não trabalham na área e nem tem pretensão de atuar como profissional contábil.

\subsection{Compreensibilidade da leitura dos estudantes envolvendo assuntos contábeis}

A compreensibilidade dos estudantes sobre assuntos contábeis envolveu: ética profissional, contabilidade I, contabilidade de custos, contabilidade tributária, auditoria, e por fim legislação trabalhista e previdenciária. Os dados demonstrados nas Tabelas apresentam as respostas corretas, erradas e nulas por fases do curso de ciências contábeis.

A Tabela 2 demonstra os resultados obtidos com a técnica Cloze para a área de ética profissional. O texto sobre ética continha 38 lacunas, considerando os 145 respondentes, totalizou 5.510 lacunas. Destas 2.231 (40\%) foram respondidas corretamente, 1.847 (34\%) foram respondidas com palavras diferentes das que foram retiradas e que não davam sentido ao texto e 1.432 $(26 \%)$ foram deixadas em branco.

Tabela 2 - Técnica Cloze sobre ética profissional

\begin{tabular}{l|c|c|c|c|c|c}
\hline Fases & $\begin{array}{c}\text { Respostas } \\
\text { Corretas }\end{array}$ & $\begin{array}{c}\% \\
\text { Respostas } \\
\text { Corretas } \\
\text { (média) }\end{array}$ & $\begin{array}{c}\text { Respostas } \\
\text { Erradas }\end{array}$ & $\begin{array}{c}\% \\
\text { Respostas } \\
\text { Erradas } \\
\text { (média) }\end{array}$ & $\begin{array}{c}\text { Respostas } \\
\text { Nulas }\end{array}$ & $\begin{array}{c}\% \\
\text { Respostas } \\
\text { Nulas } \\
\text { (média) }\end{array}$ \\
\hline $1^{a}$ Fase & 540 & $41 \%$ & 455 & $34 \%$ & 335 & $25 \%$ \\
$2^{a}$ Fase & 295 & $43 \%$ & 245 & $36 \%$ & 144 & $21 \%$ \\
$3^{a}$ Fase & 260 & $38 \%$ & 196 & $29 \%$ & 228 & $33 \%$ \\
$4^{a}$ Fase & 194 & $46 \%$ & 167 & $40 \%$ & 57 & $14 \%$ \\
$5^{a}$ Fase & 315 & $41 \%$ & 265 & $35 \%$ & 180 & $24 \%$ \\
$6^{a}$ Fase & 166 & $44 \%$ & 122 & $32 \%$ & 92 & $24 \%$ \\
$7^{a}$ Fase & 214 & $38 \%$ & 158 & $28 \%$ & 198 & $35 \%$ \\
$8^{a}$ Fase & 68 & $45 \%$ & 73 & $48 \%$ & 11 & $7 \%$ \\
\hline Outros & 179 & $34 \%$ & 166 & $31 \%$ & 187 & $35 \%$ \\
\hline Total & 2231 & - & 1847 & - & 1432 & - \\
\hline
\end{tabular}

Fonte: Dados da pesquisa.

De acordo com Silva (2005), para realizar a leitura e compreensão, é indispensável o conhecimento prévio sobre o assunto do qual se lê. Desta forma pode-se deduzir que por esta disciplina ter envolvimentos com todas as áreas de atuação e por ser um assunto habitual, há um prévio conhecimento do assunto relacionado à ética profissional, tanto que o nível de compreensão de leitura entre os estudantes de todas as fases varia de $46 \%$ a $34 \%$. O maior percentual de acertos foi apresentado por estudantes da quarta fase (46\%), que inclusive ainda não tiveram o contato com a disciplina na graduação. 
O texto sobre Contabilidade I continha 33 lacunas, considerando os 145 respondentes, totalizou 4.785 lacunas. Os maiores percentuais de acertos corresponderam aos respondentes da primeira e quarta fase, bem como o número máximo de acertos, observando os questionários de forma individual, é representado por 30 acertos de um estudante da primeira fase.

Tabela 3 - Técnica Cloze sobre contabilidade I

\begin{tabular}{|c|c|c|c|c|c|c|}
\hline Fases & $\begin{array}{c}\text { Respostas } \\
\text { Corretas }\end{array}$ & $\begin{array}{c}\% \\
\text { Respostas } \\
\text { Corretas } \\
\text { (média) }\end{array}$ & $\begin{array}{l}\text { Respostas } \\
\text { Erradas }\end{array}$ & $\begin{array}{c}\% \\
\text { Respostas } \\
\text { Erradas } \\
\text { (média) }\end{array}$ & $\begin{array}{c}\text { Respostas } \\
\text { Nulas }\end{array}$ & $\begin{array}{c}\% \\
\text { Respostas } \\
\text { Nulas } \\
\text { (média) }\end{array}$ \\
\hline $1^{a}$ Fase & 482 & $42 \%$ & 405 & $35 \%$ & 268 & $23 \%$ \\
\hline $2^{a}$ Fase & 147 & $25 \%$ & 202 & $34 \%$ & 245 & $41 \%$ \\
\hline $3^{a}$ Fase & 195 & $33 \%$ & 183 & $31 \%$ & 216 & $36 \%$ \\
\hline $4^{a}$ Fase & 155 & $43 \%$ & 155 & $43 \%$ & 53 & $15 \%$ \\
\hline $5^{a}$ Fase & 249 & $38 \%$ & 194 & $29 \%$ & 217 & $33 \%$ \\
\hline $6^{a}$ Fase & 122 & $37 \%$ & 101 & $31 \%$ & 107 & $32 \%$ \\
\hline $7^{a}$ Fase & 188 & $38 \%$ & 134 & $27 \%$ & 173 & $35 \%$ \\
\hline $8^{a}$ Fase & 47 & $36 \%$ & 58 & $44 \%$ & 27 & $20 \%$ \\
\hline Outros & 173 & $37 \%$ & 146 & $32 \%$ & 143 & $31 \%$ \\
\hline Total & 1758 & - & 1578 & - & 1449 & - \\
\hline
\end{tabular}

Fonte: Dados da pesquisa.

Observa-se que a média de respostas corretas das fases iniciais $\left(1^{a}\right.$ a $\left.4^{a}\right)$, mesmo que apresentando pouca diferença, é menor se comparada à média de acertos das fases finais $\left(5^{a}\right.$ a $\left.8^{a}\right)$. Deste modo, pode-se dizer que este estudo encontra resultado similar ao estudo de Santos et al. (2006).

Os percentuais de todas as fases poderiam ter sido maiores, por se tratar de um assunto básico do curso. O que poderia explicar este baixo desempenho é a referência do livro que foi retirado o texto aplicado à técnica Cloze, podendo não ter sido utilizado pelos professores que lecionaram a disciplina para os respectivos estudantes, mesmo se tratando de referências retiradas do plano de ensino pedagógico da Instituição.

Todos os textos foram retirados de referências do plano de ensino, conforme mencionado nos procedimentos da pesquisa. Na Tabela 4 demonstra os resultados envolvendo contabilidade de custos. 
Tabela 4 - Técnica Cloze sobre contabilidade de custos

\begin{tabular}{|c|c|c|c|c|c|c|}
\hline Fases & $\begin{array}{c}\text { Respostas } \\
\text { Corretas }\end{array}$ & $\begin{array}{c}\% \\
\text { Respostas } \\
\text { Corretas } \\
\text { (média) }\end{array}$ & $\begin{array}{c}\text { Respostas } \\
\text { Erradas }\end{array}$ & $\begin{array}{c}\% \\
\text { Respostas } \\
\text { Erradas } \\
\text { (média) }\end{array}$ & $\begin{array}{l}\text { Respostas } \\
\text { Nulas }\end{array}$ & $\begin{array}{c}\% \\
\text { Respostas } \\
\text { Nulas } \\
\text { (média) }\end{array}$ \\
\hline $1^{a}$ Fase & 368 & $23 \%$ & 563 & $35 \%$ & 679 & $42 \%$ \\
\hline $2^{a}$ Fase & 89 & $11 \%$ & 158 & $19 \%$ & 581 & $70 \%$ \\
\hline $3^{a}$ Fase & 254 & $31 \%$ & 237 & $29 \%$ & 337 & $41 \%$ \\
\hline $4^{a}$ Fase & 161 & $32 \%$ & 250 & $49 \%$ & 95 & $19 \%$ \\
\hline $5^{a}$ Fase & 320 & $35 \%$ & 268 & $29 \%$ & 332 & $36 \%$ \\
\hline $6^{a}$ Fase & 109 & $24 \%$ & 130 & $28 \%$ & 221 & $48 \%$ \\
\hline $7^{a}$ Fase & 148 & $20 \%$ & 141 & $20 \%$ & 411 & $60 \%$ \\
\hline $8^{a}$ Fase & 52 & $28 \%$ & 79 & $43 \%$ & 53 & $29 \%$ \\
\hline Outros & 147 & $23 \%$ & 170 & $26 \%$ & 327 & $51 \%$ \\
\hline Total & 1638 & - & 1996 & - & 3036 & - \\
\hline
\end{tabular}

Fonte: Dados da pesquisa.

O texto sobre Contabilidade de Custos continha 46 lacunas, considerando os 145 respondentes, totalizou 6.670 lacunas. Verificou-se um número expressivo de lacunas deixadas em branco no texto de contabilidade de custos. Principalmente na $2^{a}$ fase, em que as respostas nulas correspondem a $70 \%$ do total das lacunas e as preenchidas corretamente apenas $11 \%$.

A $5^{a}$ fase apresentou melhor desempenho de compreensibilidade de leitura, chegando a $35 \%$ de respostas corretas. Já a $4^{a}$ fase indicou não ter conhecimento prévio sobre este assunto, atingindo $49 \%$ das palavras preenchidas erradas. Tal fato pode ser esclarecido, por se tratar de um tema específico que geralmente se adquire maior conhecimento na prática, no entanto apenas $22 \%$ dos acadêmicos da $2^{a}$ fase trabalham na área contábil.

Justificando o fato, Franco (1999) relata a importância de habilidades, incluindo aquelas que possam ser criadas a partir de experiências e convívios. Neste mesmo sentido, Vale (2007) evidencia que a qualificação de cada indivíduo é construída por meio do conhecimento repassado pela instituição, pelas próprias iniciativas pessoais e pelas habilidades adquiridas na prática profissional.

Para avaliar a compreensibilidade de leitura sobre contabilidade tributária foi utilizado um texto com 32 lacunas, considerando os 145 respondentes, totalizou 4.640 lacunas. Observa-se, de maneira geral que os respondentes apresentam baixa compreensibilidade de leitura em relação ao tema. A fase que se destaca pelo menor percentual de acertos é a $2^{a}$ fase. 
Tabela 5 - Técnica Cloze sobre contabilidade tributária

\begin{tabular}{|c|c|c|c|c|c|c|}
\hline Fases & $\begin{array}{c}\text { Respostas } \\
\text { Corretas }\end{array}$ & $\begin{array}{c}\% \\
\text { Respostas } \\
\text { Corretas } \\
\text { (média) }\end{array}$ & $\begin{array}{c}\text { Respostas } \\
\text { Erradas }\end{array}$ & $\begin{array}{c}\% \\
\text { Respostas } \\
\text { Erradas } \\
\text { (média) }\end{array}$ & $\begin{array}{c}\text { Respostas } \\
\text { Nulas }\end{array}$ & $\begin{array}{c}\% \\
\text { Respostas } \\
\text { Nulas } \\
\text { (média) }\end{array}$ \\
\hline $1^{a}$ Fase & 367 & $33 \%$ & 454 & $41 \%$ & 299 & $27 \%$ \\
\hline $2^{a}$ Fase & 37 & $6 \%$ & 39 & $7 \%$ & 500 & $87 \%$ \\
\hline $3^{a}$ Fase & 126 & $22 \%$ & 147 & $26 \%$ & 303 & $53 \%$ \\
\hline $4^{a}$ Fase & 104 & $30 \%$ & 165 & $47 \%$ & 83 & $24 \%$ \\
\hline $5^{a}$ Fase & 198 & $31 \%$ & 204 & $32 \%$ & 238 & $37 \%$ \\
\hline $6^{a}$ Fase & 90 & $28 \%$ & 96 & $30 \%$ & 134 & $42 \%$ \\
\hline $7^{a}$ Fase & 111 & $23 \%$ & 109 & $23 \%$ & 260 & $54 \%$ \\
\hline $8^{a}$ Fase & 24 & $19 \%$ & 62 & $48 \%$ & 42 & $33 \%$ \\
\hline Outros & 111 & $25 \%$ & 124 & $28 \%$ & 213 & $48 \%$ \\
\hline Total & 1168 & - & 1400 & - & 2072 & - \\
\hline
\end{tabular}

Fonte: Dados da pesquisa.

Esta mesma fase possui o menor percentual também de respostas erradas, concluindo que os respondentes deixaram a maioria das lacunas em branco. Vale destacar que o desvio padrão da $2^{a}$ fase, analisado de forma individual por fase, em relação aos acertos foi de 4,8, o menor índice comparado com as outras fases.

Assim como a contabilidade de custos, a contabilidade tributária é uma área da contabilidade que necessita da prática, neste sentido o baixo percentual de compreensibilidade de leitura dos estudantes neste tema pode se justificar por não estarem trabalhando na área. Referente ao tema de auditoria, utilizou-se um texto com 41 lacunas para aplicação da técnica Cloze, considerando os 145 respondentes, totalizou 5.945 lacunas. Comparando com as demais análises, apresenta-se o maior percentual de respostas nulas (92\%), este corresponde a questionários da $3^{a}$ fase. Tal resultado ocorreu talvez por se tratar de um tema que não é habitual a todos.

Tabela 6 - Técnica Cloze sobre auditoria

\begin{tabular}{l|c|c|c|c|c|c}
\hline Fases & $\begin{array}{c}\text { Respostas } \\
\text { Corretas }\end{array}$ & $\begin{array}{c}\% \\
\text { Respostas } \\
\text { Corretas } \\
\text { (média) }\end{array}$ & $\begin{array}{c}\text { Respostas } \\
\text { Erradas }\end{array}$ & $\begin{array}{c}\% \\
\text { Respostas } \\
\text { Erradas } \\
\text { (média) }\end{array}$ & $\begin{array}{c}\text { Respostas } \\
\text { Nulas }\end{array}$ & $\begin{array}{c}\% \\
\text { Respostas } \\
\text { Nulas } \\
\text { (média) }\end{array}$ \\
\hline $\mathbf{1}^{\text {a } \text { Fase }}$ & 215 & $15 \%$ & 438 & $31 \%$ & 782 & $54 \%$ \\
$\mathbf{2}^{\text {a } \text { Fase }}$ & 56 & $8 \%$ & 72 & $10 \%$ & 610 & $83 \%$
\end{tabular}




\begin{tabular}{l|l|l|l|l|l|l}
$\mathbf{3}^{\text {a }}$ Fase & 36 & $5 \%$ & 20 & $3 \%$ & 682 & $92 \%$ \\
$\mathbf{4}^{\text {a }}$ Fase & 94 & $21 \%$ & 184 & $41 \%$ & 173 & $38 \%$ \\
$\mathbf{5}^{\text {a }}$ Fase & 126 & $15 \%$ & 175 & $21 \%$ & 519 & $63 \%$ \\
$\mathbf{6}^{\text {a }}$ Fase & 51 & $12 \%$ & 78 & $19 \%$ & 281 & $69 \%$ \\
$\mathbf{7}^{\text {a }}$ Fase & 41 & $7 \%$ & 97 & $16 \%$ & 477 & $78 \%$ \\
$\mathbf{8}^{\text {a Fase }}$ & 18 & $11 \%$ & 81 & $49 \%$ & 65 & $40 \%$ \\
Outros & 72 & $13 \%$ & 151 & $26 \%$ & 351 & $61 \%$ \\
\hline Total & 709 & - & 1296 & - & 3940 & - \\
\hline
\end{tabular}

Fonte: Dados da pesquisa.

Observa-se que a primeira e a quinta fase demonstraram maior percentual de acerto, sendo de $15 \%$ de compreensibilidade de leitura sobre auditoria, respectivamente. Tal fato pode ser explicado, de acordo com Andrade (2004) ao dizer que diante de um mesmo texto, é possível a interpretação diferenciada dos leitores, o que pode ser extremamente complexo para um, poderá ser obvio para outro. O texto sobre Legislação Trabalhista e Previdenciária continha 52 lacunas, considerando os 145 respondentes, totalizou 7.540 lacunas, conforme se observa na Tabela 7.

Tabela 7 1- Técnica Cloze sobre legislação trabalhista e previdenciária

\begin{tabular}{|c|c|c|c|c|c|c|}
\hline Fases & $\begin{array}{c}\text { Respostas } \\
\text { Corretas }\end{array}$ & $\begin{array}{c}\% \\
\text { Respostas } \\
\text { Corretas } \\
\text { (média) }\end{array}$ & $\begin{array}{c}\text { Respostas } \\
\text { Erradas }\end{array}$ & $\begin{array}{c}\% \\
\text { Respostas } \\
\text { Erradas } \\
\text { (média) }\end{array}$ & $\begin{array}{c}\text { Respostas } \\
\text { Nulas }\end{array}$ & $\begin{array}{c}\% \\
\text { Respostas } \\
\text { Nulas } \\
\text { (média) }\end{array}$ \\
\hline $1^{a}$ Fase & 354 & $19 \%$ & 611 & $34 \%$ & 855 & $47 \%$ \\
\hline $2^{a}$ Fase & 80 & $9 \%$ & 92 & $10 \%$ & 764 & $82 \%$ \\
\hline $3^{a}$ Fase & 110 & $12 \%$ & 124 & $13 \%$ & 702 & $75 \%$ \\
\hline $4^{a}$ Fase & 145 & $25 \%$ & 235 & $41 \%$ & 192 & $34 \%$ \\
\hline $5^{a}$ Fase & 287 & $28 \%$ & 336 & $32 \%$ & 417 & $40 \%$ \\
\hline $6^{a}$ Fase & 81 & $16 \%$ & 131 & $25 \%$ & 308 & $59 \%$ \\
\hline $7^{a}$ Fase & 127 & $16 \%$ & 200 & $26 \%$ & 453 & $58 \%$ \\
\hline $8^{a}$ Fase & 46 & $22 \%$ & 92 & $44 \%$ & 70 & $34 \%$ \\
\hline Outros & 138 & $19 \%$ & 182 & $25 \%$ & 408 & $56 \%$ \\
\hline Total & 1368 & - & 2003 & - & 4169 & - \\
\hline
\end{tabular}

Fonte: Dados da pesquisa.

Verificou-se que a compreensibilidade dos estudantes sobre Legislação Trabalhista e Previdenciária é muito inferior ao esperado. No mesmo sentido da

16 Revista Contabilidade Vista \& Revista, ISSN 0103-734X, Universidade Federal de Minas Gerais, Belo Horizonte, v. 29, n. 1, p.01-27, jan./abr. 2018 
análise sobre o tema de auditoria, a maioria dos estudantes deixaram de preencher mais da metade das lacunas. A $5^{a}$ fase teve o maior percentual $(28 \%)$ de compreensibilidade de leitura, e o menor percentual (9\%) de compreensibilidade de leitura se concentra na $2^{a}$ fase.

Analisando o percentual de respostas erradas, verifica-se que a $4^{a}$ e $8^{a}$ fase apresentam percentuais expressivos de erros, $41 \%$ e $44 \%$ respectivamente. De acordo com Vicentelli, (1999) ler é atividade rotineira, entretanto, a prática da leitura não é tão simples como pode ser julgada, é preciso que o leitor compreenda o que lê, dando significado a leitura. Portanto, os resultados obtidos revelam a falta da boa leitura realizada pelos estudantes.

O objetivo da leitura, de acordo com Silva (2005), é a compreensão do que outras pessoas pensam. Portanto essa tarefa exige uma visão crítica dos assuntos lidos, desenvolvendo as tarefas de examinar, identificar, comparar, localizar, avaliar, selecionar e priorizar informações.

\subsection{Análise Comparativa da Compreensibilidade de Leitura dos Estudantes em Relação a Assuntos Contábeis}

Na Tabela 8 apresenta-se análise comparativa da compreensibilidade de leitura dos estudantes sobre assuntos contábeis.

Tabela 8 - Compreensibilidade de leitura dos estudantes sobre assuntos contábeis

\begin{tabular}{l|c|c|c|c|c|c}
\hline Textos & $\begin{array}{c}\text { Respostas } \\
\text { Corretas }\end{array}$ & $\begin{array}{c}\text { Respostas } \\
\text { Corretas } \\
\text { (média) }\end{array}$ & $\begin{array}{c}\text { Respostas } \\
\text { Erradas }\end{array}$ & $\begin{array}{c}\text { Respostas } \\
\text { Erradas } \\
\text { (média) }\end{array}$ & $\begin{array}{c}\text { Respostas } \\
\text { Nulas }\end{array}$ & $\begin{array}{c}\% \\
\text { Respostas } \\
\text { Nulas } \\
\text { (média) }\end{array}$ \\
\hline $\begin{array}{l}\text { Ética profissional } \\
\text { Contabilidade I }\end{array}$ & 2231 & $40 \%$ & 1847 & $34 \%$ & 1432 & $26 \%$ \\
$\begin{array}{l}\text { Contabilidade } \\
\text { de Custos }\end{array}$ & 1758 & $37 \%$ & 1578 & $33 \%$ & 1449 & $30 \%$ \\
$\begin{array}{l}\text { Contabilidade } \\
\text { Tributária }\end{array}$ & 1168 & $25 \%$ & 1400 & $30 \%$ & 2072 & $45 \%$ \\
$\begin{array}{l}\text { Auditoria } \\
\text { Legislação }\end{array}$ & 709 & $12 \%$ & 1296 & $22 \%$ & 3940 & $66 \%$ \\
$\begin{array}{l}\text { Trabalhista } \\
\text { Previdenciária }\end{array}$ & 1368 & $18 \%$ & 2003 & $27 \%$ & 4169 & $55 \%$ \\
\hline \begin{tabular}{l} 
Total \\
\hline Total \%
\end{tabular} & $25 \%$ & - & $29 \%$ & - & $46 \%$ & - \\
\hline
\end{tabular}

Fonte: Dados da pesquisa.

Conforme Tabela 8, o texto sobre ética profissional foi o tema com maior percentual de compreensibilidade em leitura (40\%), seguido do texto de 
contabilidade I, que envolveu assunto básico de contabilidade, este representando $37 \%$ de compreensibilidade. O texto de auditoria teve o menor percentual de compreensibilidade de leitura e maior número de lacunas deixadas em branco.

Para identificar os percentuais dos totais de respostas corretas, erradas e nulas, respectivamente, evidenciado na Tabela 8 , utilizaram-se os resultados obtidos na aplicação da técnica Cloze com o total de lacunas (35.090) que compuseram os questionários a serem preenchidos.

As disciplinas de Contabilidade de Custos da $3^{a}$ fase e Contabilidade Tributária da $4^{\mathrm{a}}$ fase obtiveram os mesmos percentuais em todos os quesitos, em que as respostas nulas (45\%) foram maiores que as respostas corretas $(25 \%)$ e respostas erradas (30\%). Por se tratarem de temas mais específicos, Silva (2003) explica que os estudantes da área contábil sentem dificuldade em compreensão de textos filosóficos e técnicos, desta área. Segundo Silva (2003), supõe-se que por falta de leitura essas dificuldades se agravam.

Observa-se ainda, em uma visão geral de todos os assuntos, que há grande dificuldade de compreensibilidade na leitura em relação a assuntos contábeis dos estudantes de Ciências Contábeis, sendo que as lacunas em branco (46\%) superaram o número de acertos (25\%). Este baixo percentual de compreensibilidade em todos os temas não se justifica pelas referências utilizadas, pois de acordo com Silva (2005) o leitor que tem habilidade e competência vai compreender o texto independente da linguagem utilizada pelo autor.

\section{CONSIDERAÇÕES FINAIS}

Diante dos resultados analisados pode-se constatar que a grande maioria dos estudantes não possuíram habilidades de leitura suficientes para completar a técnica Cloze. Isso porque em nenhum dos 6 (seis) assuntos o percentual de acertos no teste, em uma visão geral de todas as fases, ultrapassou $40 \%$.

O fato de que o respondente esteja cursando fases finais do curso, não significa que este tenha maior compreensibilidade de leitura sobre os temas da graduação, pois o percentual de erros envolvendo a oitava fase do curso é fator preocupante para a instituição, pressupondo que os estudantes deveriam ter maior percepção dos assuntos e maior compreensibilidade dos itens analisados na pesquisa e que demonstraram um percentual de erros maiores em relação às demais fases envolvendo os assuntos de ética, contabilidade I, contabilidade tributária, auditoria e legislação trabalhista e previdenciária.

Acredita-se, com base nos resultados apresentados pela última fase do curso (oitava), que é necessário inserir uma quantidade maior de questões de raciocínio lógico e discursivo em avaliações, a fim de aumentar a capacidade de interpretação dos textos envolvendo as disciplinas, e melhor preparar os estudantes para as provas do ENADE e exame de suficiência do CFC.

A segunda fase apresentou maior percentual de questões nulas, seguido da terceira fase. Possivelmente isso ocorreu, pois muitos estudantes estavam na fase inicial do curso e algumas disciplinas são específicas de fases superiores. Porém, demonstra a insegurança dos estudantes em pelo menos tentar responder

18 Revista Contabilidade Vista \& Revista, ISSN 0103-734X, Universidade Federal de Minas Gerais, Belo Horizonte, v. 29, n. 1, p.01-27, jan./abr. 2018 
aos questionamentos. Diante disto, é possível sugerir aos professores, que instiguem a leitura dos acadêmicos envolvendo assuntos correlatos à área contábil, tanto por meio de livros, quanto por meio de artigos científicos, para auxiliar na interpretação de textos técnicos.

Um ponto positivo para a IES analisada é que a quarta fase, em que os estudantes estão com praticamente metade do curso concluído, apresentaram percentual maior de acertos da Técnica Cloze envolvendo os assuntos abordados, se comparado com as demais fases (iniciais e finais), o que demonstra o interesse e a compreensão de leitura desses estudantes sobre os temas. Nessa perspectiva, é relevante destacar que nem sempre o estudante precisa estar em fases finais para conseguir compreender um texto, supondo que os professores instigam a leitura constante antes e a partir dessa fase, bem como demonstra uma inteiração com os assuntos pertinentes à área, seja pela participação nas aulas, ou no convívio com o mercado de trabalho (contabilidades ou áreas afins). Porém pressupõe-se que uma maior cobrança por parte dos professores com leituras adicionais à disciplina, bem como aquisição de livros atuais sobre os temas abordados poderia contribuir com uma melhor compreensão dos assuntos contábeis pelos estudantes.

Considerando o rigor metodológico para o desenvolvimento do estudo, destacam-se duas limitações de pesquisa. A primeira limitação relaciona-se aos aspectos teóricos em relação à seleção dos textos utilizados para a análise, haja vista que o estudo não abordou todas as disciplinas do curso de ciências contábeis e a literatura apresenta diversificados assuntos relacionados à área contábil. Outra limitação é de caráter metodológico e relaciona-se ao viés dos respondentes quanto ao questionário aplicado, considerando a subjetividade no entendimento do respondente ao ler e interpretar as questões envolvendo a técnica Cloze.

Diante das limitações, recomenda-se para pesquisas futuras utilizar textos de outras disciplinas do curso a fim de verificar a compreensibilidade dos estudantes. Outra recomendação seria replicar o estudo envolvendo as questões estudadas em universidades particulares para fins comparativos. Utilizar outras técnicas para identificar o grau de compreensibilidade dos assuntos envolvendo o profissional contábil também seria relevante para a área.

\section{REFERÊNCIAS}

ADELBERG, A. H. A Methodology for Measuring the Understandability of Financial Report Messages. Journal of Accounting Research, v. 17, n. 2, p. 565-592, 1979.

; RAZEK, J. R. The cloze Procedure: a methodology for determining the understandability of accounting textbooks. The accounting review, v. 59, 1984.

ALDERSON, J. C. The testing of reading. In: Nuttal, C. Teaching reading skills in a foreign language. Oxford: Heinemann, 1996.

ALVAREZ, M. S. Entrenamiento en comprensión lectora utilizando la tecnica de Cloze con estudiantes del primer semestre de educación superior.

Transinformação, v. 2, p. 99-113, 1990. 
AMARAL, L. M. F. Governança Tributária na prática. Disponível em: http://www.governancatributaria.com.br/. Acesso em 20 maio 2014.

ANDRADE, J. X.; MARTINS, G. A. Compreensibilidade de livros-texto de contabilidade: um estudo empírico com a utilização da técnica Cloze. In.: CONGRESSO USP DE CONTROLADORIA E CONTABILIDADE, 4., 2003. São Paulo. Anais... São Paulo, 2003.

ANDRADE, J. X. Compreensibilidade de livros-texto de contabilidade: um estudo empírico com a utilização da técnica Cloze. 2004. 99f. Dissertação (Mestrado em Contabilidade e Atuária) Faculdade de Economia, Administração e Contabilidade da Universidade de São Paulo, São Paulo, 2004.

ATTIE, W. Auditoria: conceitos e aplicações. 6. ed. Altas: São Paulo, 2011.

BOFF, M. L.; BASTOS, E. C.; DOMINGUES, M. J. C. S.; ISHIKURA, E. R. O Teste Cloze na Avaliação de Compreensão em Leitura: Um Estudo em Alunos Ingressantes e Concluintes do Curso de Ciências Contábeis. In: CONGRESSO INTERNACIONAL DE GESTÃO DA TECNOLOGIA E SISTEMAS DE INFORMAÇÃO, 5.. São Paulo. Anais... São Paulo, 2008.

BORMUTH, J. R. Cloze Test Readability: Criterion Reference scores. Journal of Education Measurement, v. 5, n. 3, p. 189-196, 1968.

BORTOLANZA, A. M. E. Leitura e Literatura para Crianças de meses a 5 anos: livros, poesias e outras ideias. In: Leitura e Cidadania. Campinas: Mercado de Letras, 2012.

CARREL, P. L; CARSON, J. G. First and second language reading strategies: evidence from cloze. Reading in a Foreign Language, v. 10, n. 1, p. 953- 965, 1993.

COSTA NETO. P. L. O. Estatística. São Paulo: Edgard Blücher, 1977.

COSTA, P. S. O teste Cloze na avaliação de aprendizagem: o caso dos alunos do curso de ciências contábeis da Universidade Federal do Rio Grande do Norte. In: CONGRESSO USP DE CONTROLADORIA E CONTABILIDADE, 6., 2006, São Paulo. Anais... São Paulo, 2006.

COSTA, P. Hábito de leitura e compreensão de textos: uma análise da realidade de pós-graduados em Administração. 2006. Dissertação (Mestrado em Administração). Universidade Federal de Santa Maria. Santa Maria, 2006.

COSTA, P. D. S.; AQUINO, D. R. B.; LIMA, D. H. S.; SANTIAGO, J. S. O Teste Cloze na Avaliação de Aprendizagem: O Caso dos Alunos da Disciplina de Contabilidade de Custos I do Curso de Ciências Contábeis da Universidade Federal do Rio Grande do Norte. In: CONGRESSO BRASILEIRO DE CUSTOS - CBC, 9, 2005, Florianópolis. Anais... Florianópolis, 2005

CUNHA, N. B. Pesquisas com o teste de Cloze no Brasil. In: SANTOS, A. A. A; Boruchovitch, E.; Oliveira, K. L. (Orgs.), Cloze: um instrumento de diagnóstico e intervenção. São Paulo: Casa do Psicólogo, 2009.

DALLABONA, L. F.; BEUREN I. M; RODRIGUES J. M. M.. Compreensibilidade de Livros de Sistemas de Informação: Um Estudo com Aplicação da Técnica Técnica Cloze em Alunos de Mestrado e de Doutorado em Ciências Contábeis. Espacios. Espácios, v. 33, n. 1, p. 11, 2012. 
DIAS, F. G. R.; SILVEIRA, M. I. M. O teste cloze de múltipla escolha na avaliação em compreensão de leitura na língua inglesa: um estudo com mestrandos da área da saúde. Work. Pap. Linguíst., v. 15, n. 1, p. 57-70, 2014.

FABRETTI, L. C. Contabilidade Tributária. $11^{a}$ ed. São Paulo. Atlas, 2007.

FRANCO, H. A contabilidade na era da globalização: temas discutidos no XV Congresso Mundial de Contadores em Paris, Paris. São Paulo: Atlas, 1999.

HORNGREN, C. T. Contabilidade de custos: um enfoque administrativo. São Paulo: Atlas, 1986.

IUDÍCIBUS S. Contabilidade introdutória. 11 ed. São Paulo: Atlas, 2010.

KLEIMAN, A. B. Diagnóstico de dificuldades na leitura: uma proposta de instrumento. Cadernos PUC, v. 16, p. 34-50, 1983.

LANG, J.; ZANCHETT, R. Compreensão de leitura a luz do teste cloze: comparação entre ingressantes e concluintes. In: CONGRESSO VIRTUAL BRASILEIRO DE ADMINISTRAÇÃO, 4., 2007. Anais... 2007.

LEFFA, V. J. Aspectos da leitura: uma perspectiva psicolingüística. Porto Alegre: Sagra/Luzzato, 1996.

LISBOA, L. P. Ética geral e profissional em contabilidade. Atlas, São Paulo, 1997.

MACHADO, N. Sistema de informação de custo: diretrizes para integração ao orçamento público e à contabilidade governamental. 2002. Tese (Doutorado em Controladoria e Contabilidade) - Programa de Pós-Graduação em Controladoria e Contabilidade, USP, São Paulo, 2002.

MARTINS, E. Contabilidade de custos. 9 ed. São Paulo: Altas, 2003.

MATTAR, F. Pesquisa de marketing. São Paulo: Atlas, 1996.

MOLINA, O. Avaliação da inteligibilidade de livros didáticos de 1. E 2. Graus por meio da técnica cloze. 1979. 185f. Tese (Doutorado em Psicologia). Instituto de Psicologia, Universidade de São Paulo, São Paulo, 1979.

MONELLO, M. R. Conselho Federal de Contabilidade. Disponível em: <http://www.portaldecontabilidade.com.br/nbc/>. Acesso em: 30 março 2015.

NASI, A. C. A Contabilidade como Instrumento de Informações, Decisão e Controle da Gestão. Revista Brasileira de Contabilidade, v. 23, n. 77, 1994

NEVES, S.; VICECONTI, P. E. V. Contabilidade Básica. 13. ed. São Paulo: Frase Editora, 2006.

OLIVEIRA, K. L.; CANTALICE, L. M.; FREITAS, F. A. Compreensão em leitura no ensino médio: análise de acertos por item. In A. A. A. Santos, E. Boruchovitch, \& K. L. Oliveira (Orgs.), Cloze: um instrumento de diagnóstico e intervenção. São Paulo, SP: Casa do Psicólogo, 2009.

PELLEGRINI, M. C. K. Avaliação dos níveis de compreensão e atitudes frente à leitura em universitários. Dissertação de mestrado não-publicada. Programa de Estudos Pós-graduados em Educação da Universidade São Francisco. Bragança Paulista, 1996.

RIBEIRO, O. M. Contabilidade Básica Fácil. 21. ed. São Paulo: Saraiva, 1997. 
SANTOS, A. A. A; PRIMI, R.; TAXA, F.; VENDRAMINI, C. M. M. O Teste de Cloze na Avaliação da Compreensão em Leitura. Psicologia: Reflexão e Crítica, v. 15, n. 3, p. 549-560, 2002.

SANTOS, A. A. A. D.; VENDRAMINI, C. M. M.; SUEHIRO, A. C. B.; SANTOS, L. A. D. D. Leitura compreensiva e utilização de estratégias de aprendizagem em alunos de Psicologia. Estudos de Psicologia, v. 23, n. 1, p. 83-91, 2006.

SÉLIS, P. S. Compreensão em leitura e estratégias de aprendizagem em universitários. 2008. 101f. Dissertação (Mestrado em Educação). Programa de Mestrado em Educação, Universidade do Oeste Paulista, Presidente Prudente, São Paulo, 2008.

SILVA, A. C. R. Metodologia da pesquisa aplicada à contabilidade: orientações de estudos, projetos, artigos, relatórios, monografias, dissertações, teses. São Paulo: Atlas, 2003.

SILVA, M.V.S.; GABRIEL, R. Leitura compreensiva e avaliação. In: COLÓQUIO LEITURA E COGNIÇÃO, 2., 2005, Santa Cruz do Sul. Anais ... Santa Cruz do Sul, 2005.

SILVA, T. M. O Profissional da contabilidade e as tendências do mundo virtual. Revista Eletrônica de Contabilidade, v. 2, n. 2, 2005.

SMITH, M.; TAFFLER, R. Readability and Understandability: Different measures of the Textual Complexity of Accounting Narrative. Accounting, Auditing e Accountability Journal, v. 5, n. 4, p. 84-98, 1992.

SOIBELMAN, L. A enciclopédia do Advogado. 3. ed. Rio de Janeiro: Rio, 1981.

STEVENS, K. C.; STEVENS, K. T.; STEVENS, W. P. A response to "measuring readability: a comparison of accounting textbooks". Journal of Accounting Education, v. 11 , p. 287-292, 1993.

TAYLOR, W. L. Cloze procedure: a new tool for measuring readability. Journalism Quarterly, 1953.

VALE, C. A. A importância da contabilidade no curso de graduação em ADMA. Revista Contábil e Empresarial, out, 2007.

VÁSQUEZ, A. S. Ética. 23. ed. Rio de Janeiro: Civilização brasileira, 2002.

VICENTELLI, H. Problemática de la lectura en estudiantes universitarios. Psicologia Escolar e Educacional, 1999.

WITTER, G. Leitura: textos e pesquisas. Campinas, Editora Alínea, 1999. 
Apêndice: Questionário
a) Gênero:
b) Idade:
( ) até 20 anos
() Feminino
( ) 21 a 25 anos
( ) Masculino
( ) 26 a 30 anos
( ) acima de 30 anos

c) Ano e Semestre que iniciou o curso em Ciências Contábeis: 201_/

d) Cursa disciplinas da(s) respectiva(s) fase(s):
( ) $1^{a}$ fase
( ) $5^{a}$ fase
( ) $2^{a}$ fase
( ) $6^{a}$ fase
( ) $3^{a}$ fase
( ) $7^{a}$ fase
( ) $4^{a}$ fase
( ) 8 fase

e) Você precisou mudar de cidade para ingressar no curso de graduação em Ciências Contábeis?
( ) Sim
( ) Não

f) Se sua resposta foi sim, qual sua cidade de origem?

g) Atualmente reside em:

h) Você trabalha na área contábil?
( ) Sim
( ) Não
() Pretende

i) Caso sua resposta anterior for negativa, em qual área você trabalha?

j) Após concluir o curso, pretende dar continuidade aos estudos, considerando uma das opçōes abaixo?

( ) Pós-Graduação/Especialização

( ) Mestrado

( ) Doutorado

( ) Graduação em outra área

( ) Nenhuma das alternativas

1 - Este é um teste para observar a compreensibilidade de leitura envolvendo conteúdo das disciplinas do curso de Ciências Contábeis. Ele é composto de textos obtidos de livros referenciados por professores nos Planos de Ensino do Curso de Ciências Contábeis do CEAVI/UDESC. Em cada texto foi retirada a quinta palavra e colocado um espaço em branco com o mesmo tamanho. A palavra a ser colocada no espaço em branco poderá ser uma palavra grande, como, por exemplo, a palavra "Administrador", ou uma palavra pequena, como, por exemplo, a palavra "o". Você deverá descobrir qual a palavra que foi retirada e escrevê-la no espaço em branco. 


\section{1 Ética Profissional em Contabilidade - Texto extraído do livro de Lázaro Plácido Lisboa (1997).}

Dentro de seu campo de atuação, a ética pode ser vista através de duas óticas distintas: (a) enquanto explicação do comportamento humano, em um período qualquer, justificando, desse modo, as ações advindas daquele comportamento, e (b) enquanto fonte para o estabelecimento de regras de comportamento diante de situações concretas, caso em que a ética se presta para, senão eliminar, pelo menos atenuar os conflitos de interesses no seio de qualquer sociedade. Em qualquer sociedade que observe, será sempre notada existência de dilemas morais seu interior. Os dilemas são um reflexo das das pessoas, e surgem partir do momento em diante de uma situação a ação de um contraria aquilo que genericamente sociedade estabeleceu como padrão comportamento para aquela situação. comportamento das pessoas, enquanto

quais um acredita, sofre alterações dos valores nos fato significa que aquilo comportamento amoral pode, a sempre foi considerado como

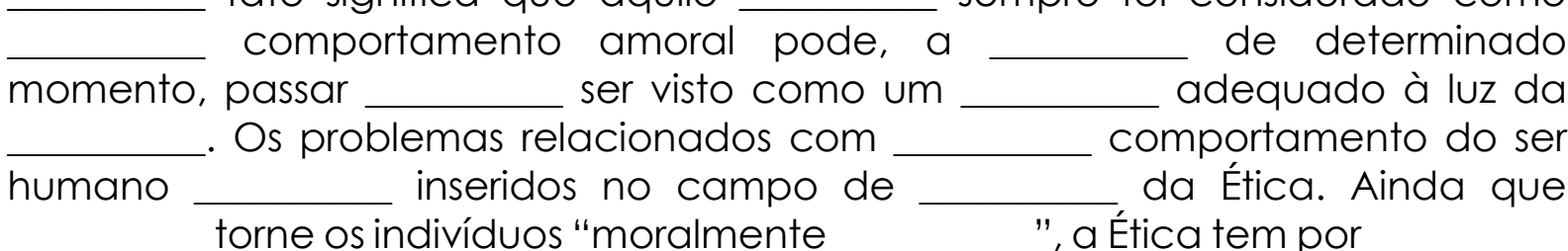
investigar e explicar o das pessoas ao longo

história. função apresenta-se como de várias fases da sentido se entender o passado, relevância, tanto no visando a fixação de comportamentos o nível de conflitos de servir como parâmetro ", aceitos pela maioria, interesses dentro da sociedade.

\subsection{Contabilidade Introdutória - Texto extraído do livro de ludícibus et al. (2010).}

Quando uma empresa necessita de fundos adicionais para prosseguimento ou expansão de suas operações, poderá recorrer aos seguintes expedientes: a) tomar dinheiro emprestado de um banco, de uma companhia de financiamento ou de um capitalista particular, para pagamento a curto ou médio prazo; b) tomar dinheiro emprestado, geralmente de um banco governamental por prazo longo; c) lançar debêntures, a médio ou longo prazo (se for sociedade por ações); d) aumentar o capital; e) etc. Os empréstimos a curto ser efetuados exclusivamente atender a necessidades que

periodicamente dentro de cada operacional, isto é, para de gastos que, normalmente, devem produtos ou serviços. Quando, recuperados com a venda instalações permanentes, o empréstimo contra-indicado. esse tipo de investimento, qualquer outro caráter permanente, as demais citadas são de acordo com as cujo prazo de pagamento empréstimos a curto prazo até, no máximo, 360 Tais empréstimos podem ser por meio de um _ de uma companhia de ou de um capitalista Para simbolizar o raciocínio, que nossa empresa opere com bancos. Em contrapartida empréstimo

24 Revista Contabilidade Vista \& Revista, ISSN 0103-734X, Universidade Federal de Minas Gerais, Belo Horizonte, v. 29, n. 1, p.01-27, jan./abr. 2018 
recebido, somos obrigados

fornecer certa garantia ao

. Essa

garantia pode ser bens (hipotecando-os ou empenhando-os) fiduciária (entregando Duplicatas a de nossos clientes ou promissórias).

\subsection{Contabilidade de Custos - Texto extraído do livro de Eliseu Martins (2003).}

Além de seu agrupamento em Direitos e Indiretos, os custos podem ser classificados de outras formas diferentes. Outra classificação usual (e importante que todas as relação entre ) é a que leva numa unidade de tempo. valor total de um consideração a Variáveis. Por exemplo, basicamente os Custos em e o volume de diretos por mês valor global de consumo quantidade produzida, uma unidade de tempo tais materiais materiais diretos fabrica aumentos diretamente do volume de materiais . Quanto maior a seu consumo. Dentro, portanto, nesse exemplo), o valor custo com de acordo com volume produção; logo, Custos Variáveis. Por outro o aluguel da produtos. Por certo mês é de valor, independentemente de notar que a classificação diminuições naquele mês do o aluguel é um Fixo. É de grande elaborado de a unidade de Fixos e Variáveis leva consideração de tempo e o o valor total de com um item nessa de atividade. Não se como no caso da de Diretos e Indiretos, um relacionamento com a produzida. Por exemplo, a é um Custo Variável, mês, seu total consumido depende da Entretanto, unidade elaborada a quantidade de que, por prima é provavelmente a ; mas isso não the matériade Variável; contrário, reforça-a.

\subsection{Contabilidade Tributária - Texto extraído do livro de Láudio Camargo Fabretti (2007).}

O objeto da contabilidade tributaria é apurar com exatidão o resultado econômico do exercício social, demonstrando-o de forma clara e sintética, para, em seguida, atender de forma extracontábil às exigências das legislações do IRPJ e da Contribuição Social sobre o Lucro, determinado a base de cálculo fiscal para formação das provisões destinadas ao pagamento desses tributos, as quais serão abatidas do resultado econômico (contábil), para determinação do lucro líquido à disposição dos acionistas, sócios ou titular de firma individual. Para atingir plenamente esse é preciso estudar, registrar controlar os atos e administrativos que produzem mutações positivo ou negativo (lucro consequentemente o resultado escrituração contábil. Já as prejuízo). Isso se faz bases de cálculo do fiscais para a determinação bases de e da CSL são de forma extracontábil no de___ do Lucro Real (Lalur). tudo, bom-senso do planejador. fiscal denominado Livro
planejamento tributário exige, antes
alternativas legais válidas empresas, mas que são para as medias e 
planejamento podem exigir. A avaliada. Não há mágica relações custo/beneficio variam muito época, do local etc. custo/benefício dever ser muito planejamento tributário, apenas alternativas, pagamento do IRPJ e

dos valores envolvidos, contabilidade, abatendo-os resultado econômico provisões função os valores das

1.5 Auditoria - Texto extraído do livro de Wiliam Attie (1998).

A complexidade e o volume das operações fazem com que os procedimentos de auditoria sejam aplicados por meio de provas seletivas, testes e amostragem, cabendo ao auditor, com base no controle interno e nos elementos de juízo de que dispõe, determinar o número de operações a serem examinadas, para obter elementos de convicção que sejam válidos para o todo. A natureza, a extensão a profundidade dos procedimentos

aplicados de investigações e da

Para o auditor, a da prova está em auditoria a serem origem e com base a prova obtida diretamente

fonte externa proporciona maior de confiança do que

obtida internamente, assim como verificação e pessoal do auditor _ obtido indiretamente. O objetivo conhecimento obtido por sobre as demonstrações financeiras

acerca propriedade das mesmas, e da prova a ser do elemento que the

especificamente desvendar fraudes e outras maior validade do que um exame normal de expressar uma opinião , não é destinado

efetuar seu e ao expressar sua . Entretanto, a financeiras, auditor deve estar alerta existência destes, em alguns casos podem sobre as demonstrações possibilidade da que a posição patrimonial e de tal grandeza da empresa em exame. caso de descoberta de auditor estudar relevância e os possíveis em exame para a cabe ao demonstrações divulgação à administração da e confidencial.

\subsection{Legislação Trabalhista e Previdenciária - Texto extraído do livro de Nascimento (2009).}

Remuneração: Durante as férias a remuneração do empregado será a mesma, como se tivesse em serviço, coincidindo com a do dia da concessão, acrescida de um terço (CF, art, $\left.7^{\circ}, \mathrm{XVII}\right)$. Quando o salário for jornadas será calculada a média por hora, com período e sobre esse número horas trabalhadas no do dia da concessão.

produção, será calculada média o valor unitário da o salário é pago em relação às de seu parecer auditada de forma sigilosa e sobre esse número concessão. Se o salário pago por comissão ou apurar-se-á a média dos_dos 12 meses anteriores concessão. Se o salário ___ pago parcialmente em utilidades, valor desta será computado remuneração, salvo se durante férias o empregado continuar da utilidade. Os adicionais 
como de horas extras, etc., integram a remuneração

férias.

Se na época

tirada percentuais

Abono de férias (CLT, art. 143). em dinheiro. A natureza média do período aquisitivo, dos : É o pagamento em lei não permite a fazer. No entanto, permite das férias é, em de adicionais, será atualização dos salariais coletivos. em troca do gozo total das férias em lugar, a conversão quanto de obrigação férias. Assim, abono de a $1 / 3$ férias. Assim, abor
uração de férias da duração de féric
de dias de férias do de dias de férias dinheiro. Provocará a redução aumentará o ganho do de férias", parece-nos que abono de férias atrita-se Contudo, é prática a Constituição (CF, art. nas relações de trabalho. 